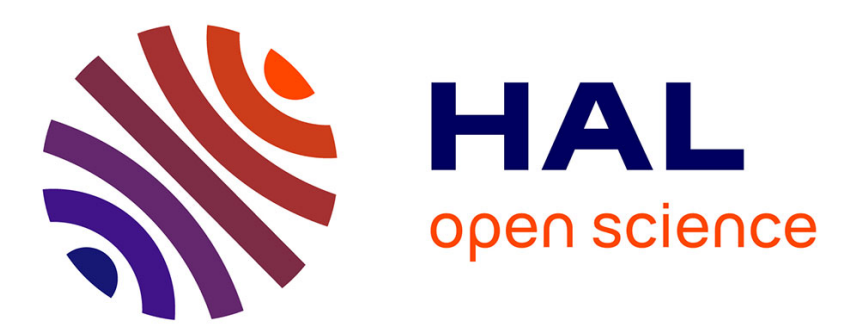

\title{
Dynamic business continuity assessment using condition monitoring data
}

Jinduo Xing, Zhiguo Zeng, Enrico Zio

\section{To cite this version:}

Jinduo Xing, Zhiguo Zeng, Enrico Zio. Dynamic business continuity assessment using condition monitoring data. International Journal of Disaster Risk Reduction, 2019, 41, pp.101334. 10.1016/j.ijdrr.2019.101334 . hal-02428516

\section{HAL Id: hal-02428516 https://hal.science/hal-02428516}

Submitted on 13 Jan 2020

HAL is a multi-disciplinary open access archive for the deposit and dissemination of scientific research documents, whether they are published or not. The documents may come from teaching and research institutions in France or abroad, or from public or private research centers.
L'archive ouverte pluridisciplinaire HAL, est destinée au dépôt et à la diffusion de documents scientifiques de niveau recherche, publiés ou non, émanant des établissements d'enseignement et de recherche français ou étrangers, des laboratoires publics ou privés. 


\section{Dynamic business continuity assessment using condition monitoring data}

Jinduo Xing ${ }^{1}$, Zhiguo Zeng ${ }^{1}$, Enrico Zio ${ }^{2,3,4}$

${ }^{1}$ Chair System Science and the Energy Challenge, Fondation Electricité de France (EDF), CentraleSupélec, Université Paris Saclay, Gif-sur-Yvette, France

${ }^{2}$ MINES ParisTech, PSL Research University, CRC, Sophia Antipolis, France

${ }^{3}$ Energy Department, Politecnico di Milano, Milan, Italy

${ }^{4}$ Eminent Scholar, Department of Nuclear Engineering, College of Engineering, Kyung Hee University, Republic of Korea

jinduo.xing@centralesupelec.fr, zhiguo.zeng@centralesupelec.fr, enrico.zio@polimi.it

Abstract

Concerns on the impacts of disruptive events of various nature on business operations have increased significantly during the past decades. In this respect, business continuity management (BCM) has been proposed as a comprehensive and proactive framework to prevent the disruptive events from impacting the business operations and reduce their potential damages. Most existing business continuity assessment (BCA) models that numerically quantify the business continuity are time-static, in the sense that the analysis done before operation is not updated to consider the aging and degradation of components and systems which influence their vulnerability and resistance to disruptive events. On the other hand, condition monitoring is more and more adopted in industry to maintain under control the state of components and systems. On this basis, in this work, a dynamic and quantitative method is proposed to integrate in BCA the information on the conditions of components and systems. Specifically, a particle filtering-based method is developed to integrate condition monitoring data on the safety barriers installed for system protection, to predict their reliability as their condition changes due to aging. An installment model and a stochastic price model are also employed to quantify the time-dependent revenues and tolerable losses from operating the system. A simulation model is developed to evaluate dynamic business continuity metrics originally introduced. A case study regarding a nuclear power plant (NPP) risk scenario is worked out to demonstrate the applicability of the proposed approach.

\section{Keywords}

Business continuity management (BCM), Dynamic business continuity assessment (DBCA), Condition monitoring, Prognostic and health management (PHM), Particle filtering (PF), Event tree (ET) 
30 BCA business continuity assessment

31 BCM business continuity management

32 BCV business continuity value

33 DBC dynamic business continuity

34 DBCA dynamic business continuity assessment

35 DRA dynamic risk assessment

36 ET event tree

37 MBCO minimum business continuity objective

38 MTPD maximum tolerable period of disruption

39 NPP nuclear power plant

40 PDF probability density function

$41 \quad$ PF $\quad$ particle filtering

42 PRA probabilistic risk assessment

43 RCS reactor coolant system

44 RTO recovery time objective

45 RUL remaining useful life

46 SGTR steam generator tube rupture

$47 \quad$ Notation

$48 \quad a \quad$ Crack size

$49 B C V([t, t+T]) \quad$ Business continuity value at $t$ with reference to a time horizon $T$

$50 \quad C_{o} \quad$ Operation cost

$51 \quad C_{p} \quad$ Repayment cost

$52 \quad C_{S 1} \quad$ First consequence

$53 \quad C_{S 2} \quad$ Second consequence

$54 \quad D_{p} \quad$ Down payment

$55 \quad E D B C V \quad$ Expected value of dynamic business continuity at time $t$

$56 \quad f(\cdot) \quad$ State function 
Total investment

$60 \quad L_{d}$

Direct loss

$61 L_{i n}$

Indirect loss

$62 L_{t o l}$

Tolerable loss

$63 \quad N_{s}$

Sample size of PF

$64 \quad N_{P}$

Repayment period

65

66

$P_{B F}([t, t+T])$ Probability of business failure in $[t, t+T]$

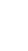

$67 \quad P_{I D}$

$P_{B I}([t, t+T])$ Probability of business interruption in $[t, t+T]$

$68 \quad q$

Indirect loss per unit of time

$69 Q_{0}$

Time length of condition monitoring

$70 t_{\text {recv }}$

Initial funding

$71 \quad T$

Recovery time

$72 \omega_{k}^{(i)}$

Time length of $\mathrm{BC}$ estimation

73

$\psi \quad$ Indicator function

$74 \rho$

Interest rate

$75 \delta_{k}$

Observation noise at $t=t_{k}$

$76 \lambda_{s t}$

Intensity of rupture event (for static business continuity)

$77 \Delta K$

Stress intensity factor

$78 \Delta \sigma$

Stress range

79 


\section{Introduction}

Business organizations are faced with threats from various disruptive events, such as natural disasters[1,2], intentional attacks [3] and hardware failures [4], etc. As reported in [5, 6], 43\% of the companies that have suffered from severe disruptive events have been permanently closed. Among these companies, around $30 \%$ failed within two years. Being prepared for disruptive events, including prevention in pre-event phase and response in post-event phase, is, then, important for modern businesses [7]. This is the reason why business continuity management (BCM) has received increasing attention in recent years as a holistic risk management method to cope with disruptive events [812]. $\mathrm{BCM}$ is formally defined in [13] as "holistic management process that identifies the potential threats to an organization and the potential impacts they may cause to business operations those threats, if realized, might cause, and which provides a framework for building organizational resilience with the capability of an effective response that safeguards the interest of its key stakeholders reputation, brand and value-creating activities". Compared to conventional risk analysis method, BCM not only focuses on the potential hazards and their impacts, but also considers how to mitigate the consequence and quickly recover from the disruption. Therefore, it provides a framework for building organizational resilience that safeguards the interests of the business stakeholders.

Most existing works mainly discuss BCM from a management perspective [14]. For instance, the necessity and benefit of implementing BCM in a supply chain has been discussed in qualitative terms in [11]. In [15], a framework for the design, implementation and monitoring of BCM programs has been proposed. In [16], the evolution of BCM related to crisis management has been reviewed, in terms of practices and drivers of BCM. In [17], BCM has been compared with conventional risk management methods, showing that $\mathrm{BCM}$ considers not only the protection of the system against the disruptive event, but also the recovery process during and after the accident. The importance of reliability and simulation in BCM has been discussed in [18]. In [19], a framework for information system continuity management has been introduced. Standards concerning BCM of the Brazilian gas supply chain have been discussed in [20]. A practice on BCM in Thailand has been reviewed and a few suggestions on BCM approaches have been presented in [21]. In [22], the conceptual foundation of BCM has been presented in the context of societal safety.

From an engineering point of view, it is needed to define numerical indexes that support quantitative business continuity assessment (BCA). A few numerical indexes have been defined in [13], e.g., maximum tolerable period of disruption (MTPD), minimum business continuity objective (MBCO) and recovery time objective (RTO). However, these numerical indexes are usually directly estimated based on expert judgements. Only a few attempts exist concerning developing quantitative models to evaluate these numerical indexes. For example, a statistical model 
integrating Cox's model and Bayesian networks has been proposed to model the business continuity process [23]. In

110 [24], a simulation model has been developed to analyze the business continuity of a company considering an outbreak

111 of pandemic disease, where the business continuity is characterized by the operation rate and the plant-utilization

112 rate. In [5], an integrated business continuity and disaster recovery planning framework has been presented and a

113 multi-objective mixed integer linear programing has been used to find efficient resource allocation patterns. In [9],

114 BCM outsourcing and insuring strategies have been compared based on the organization characteristics and the

115 relevant data through a two-step, fuzzy cost-benefit analysis. Moreover, in [10], an enhanced risk assessment

116 framework equipped with analytical techniques for BCM systems has been proposed. Two probabilistic programming

117 models have been developed to determine appropriate business continuity plans, given epistemic uncertainty of input

118 data in [25]. In [26], a new model for integrated business continuity and disaster recovery planning has been presented,

119 considering multiple disruptive incidents that might occur simultaneously. An integrated framework has been

120 developed in [12] for quantitative business continuity analysis, where four numerical metrics have been proposed to

121 quantify the business continuity level based on the potential losses caused by the disruptive events.

Most quantitative BCA models mentioned above are time-static in the sense that the analysis is performed before the system of interest comes into operation, with no further consideration of the changes that occur due to aging and degradation. In particular, in practice, business continuity is influenced by the degradation of safety barriers. On the other hand, the advancing of sensor technologies and computing resources has made it possible to retrieve information on the state of components and systems, by collecting and elaborating condition monitoring data [27, 28]. For example, a condition-based fault tree has been used for dynamic risk assessment (DRA) [29], where the condition monitoring data are used to update the failure rates of specific components and predict their reliability. In [30], a Bayesian reliability updating method has been developed for dependent components by using condition monitoring data. In [4], a holistic framework that integrates the condition monitoring data and statistical data has been proposed for DRA. A sequential Bayesian approach has been developed in [31], for dynamic reliability assessment and remaining useful life prediction for dependent competing failure processes. Usually, information fusion can add values for decision support [32]. A quantitative model for information risks in supply chain has been developed where the proposed model can be updated when new data are available [33].

In this paper, we propose a framework for DBCA that integrates condition monitoring data and allows updating the business continuity analysis using information collected during system operation. It should be noted that in this paper, we focus on "business continuity assessment" rather than "business continuity management". That is, we are 
concerning developing quantitative models to evaluate the numerical business continuity metrics, which are further used in $\mathrm{BCM}$ process as quantitative requirements. The developed model contributes to the existing research on $\mathrm{BCA}$ in three aspects:

1) An integrated DBCA model is proposed, which can provide for BCA updating in time.

2) New dynamic business continuity metrics are introduced.

3) A simulation-based algorithm is developed to calculate the dynamic business continuity metrics.

The remainder of this paper is organized as follows. In Section 2, numerical metrics for DBCA are proposed. An integrated framework of DBCA is developed in Section 3. Section 4 describes the application of the proposed framework on a nuclear power plant (NPP) accident. Section 5 discusses applicability of the proposed DBCA method. Eventually, Section 6 concludes this work.

\section{Numerical metrics for dynamic business continuity assessment}

Business process is the process of producing products or supporting services by an organization. The business process of an organization can be characterized by a performance indicator, whose value reflects the degree to which the objective of the business is satisfied. For instance, for a NPP, this indicator can be monthly electricity production. As reviewed in Section 1, there are a few numerical indexes for quantifying the continuity of a business process (MTPD, MBCO, RTO, etc.) [13]. These numerical indexes, however, focus only on one specific phase of the whole process. For example, RTO focuses only on the post-disruption recovery phase., MBCO focuses only on the postdisruption contingency activities. In this paper, we use the numerical business continuity indexes developed in [12], which are defined in a more integrated sense that they are able to cover the whole process, from pre-disruption preventions to post-disruption contingency and recovery.

In the quantitative framework developed in [12], the business continuity is quantified based on the potential losses caused by the disruptive events. The business process is divided into four sequential stages: preventive stage, mitigation stage, emergency stage and recovery stage. Various safety measures are designed in different stages to guarantee the continuity of the business process. Business continuity value (BCV) was formally defined as [12]:

$$
B C V([0, T])=1-\frac{L([0, T])}{L_{\mathrm{tol}}}
$$

where $L$ denotes the loss in $[0, T]$ from the disruptive event; $T$ is the evaluation horizon for the assessment (e.g., the lifetime of the system); $L_{\mathrm{tol}}$ is the maximum loss that can be tolerated by an organization, which manifests 
system tolerance ability against disruptive event [34]. Negative value of BCV means that $L$ is higher than $L_{\text {tol }}$, which is unacceptable for the targeted system. When $B C V=0$, it implies that the loss is exactly what the system can maximally tolerate. Regarding $B C V=1$, it means no loss has been generated. Equation (1) measures the relative distance to a financially dangerous state by taking into account the possible losses generated by the business disruption. It should be noted that only one business process is considered in this paper, while in practice, an organization might be involved in multiple business processes at the same time. For multiple-business system, the developed framework can be naturally extended based on the potential losses and profit generated by the different business processes together.

The business continuity metrics discussed above are time-static in nature. In practice, however, various factors influencing the business continuity are time-dependent. These dynamic influencing factors can be grouped into internal factors and external factors. Internal factors are related to the safety barriers within the system of interest, such as the dynamic failure behavior of the safety barriers (e.g., corrosion [35], fatigue crack [36], and wear [37]). External factors refer to the influence from external environment. For example, variations in the price of products will affect the accumulated revenue of the organization, and, then, the tolerable loss in Equation (1). To consider these factors, the business continuity metrics are extended to the dynamic cases:

$$
D B C V([t, t+T])=1-\frac{L([t, T+t])}{L_{\mathrm{tol}}(t)},
$$

where $t$ is the time instant when the dynamic business continuity assessment is carried out; $D B C V([t, t+T])$ represents the business continuity value evaluated at time $t$, for a given evaluation horizon of $T ; L([t, t+T])$ represents the potential losses in $[t, t+T] ; L_{\mathrm{tol}}(t)$ denotes the maximal amount of losses that the company can tolerate at $t$ : beyond that level of losses, it will have difficulties in recovering. It is assumed that once an organization suffer a loss beyond $L_{t o l}$, it is unable to recover from the disruption due to the financial critical situations. The physical meaning of DBCV is the relative distance to a financial dangerous state at time $t$, by considering the possible losses in $[t, t+T]$ due to business disruption; it measures the dynamic behavior of business continuity in a time interval of interest $[t, t+T]$. By calculating the DBCV at different $t$, the dynamic behavior of business continuity can be investigated. In [12], two kinds of losses need to be considered when calculating $L([t, t+T])$ : direct loss and indirect loss Direct loss, denoted by $L_{\mathrm{d}}([t, t+T])$, represents the losses that are caused directly by the disruptive event, including 
structural damage of the system. For example, in a NPP leakage event, $L_{\mathrm{d}}[t, t+T]$ includes all equipment damage directly caused by the event. Indirect loss, denoted by $L_{\mathrm{n}}([t, t+T])$, is the revenue loss suffered during the shutdown of the plant [38]. Hence, the total loss is calculated by:

$$
L([t, T+T])=L_{\mathrm{d}}([t, t+T])+L_{\text {in }}([t, t+T]) .
$$

In terms of other types of accident, for instance, workplace accidents, damages to the surroundings, etc. they may also affect the business continuity. Due to page limits, we did not include them in the developed model in this paper. However, the developed method can be naturally generalized by including more initiating events in the analysis. The DBCV defined in (2) is a random variable. Three numerical metrics are, then, proposed for its quantification:

$$
\begin{gathered}
E D B C V=E[D B C V] \\
P_{\mathrm{BI}}([t, t+T])=\operatorname{Pr}(B C V<1, t) \\
P_{\mathrm{BF}}([t, t+T])=\operatorname{Pr}(B C V<0, t)
\end{gathered}
$$

$E D B C V$ is the expected value of the dynamic business continuity value. A higher $E D B C V$ indicates higher business continuity. $P_{\mathrm{BI}}([t, t+T])$ represents the probability that at least one disruptive event causes business interruption in time interval $[t, t+T] ; P_{\mathrm{BF}}([t, t+T])$ is the probability that business failure occurs in $[t, t+T]$, i.e., of the event that the losses caused by the disruptive event are beyond $L_{t o l}$. It is assumed that once an organization suffers a loss beyond $L_{t o l}$, it is unable to recover from the disruption due to the financial critical situations. In this work, both of current time $t$ and the estimation horizon $T$ have influences on BCV. We manage to propose a real-time $\mathrm{BCA}$ by considering the time-dependent variables.

\section{An integrated framework for dynamic business continuity assessment}

In this section, we first present an integrated modeling framework for the dynamic business continuity metrics defined in Section 2. Then, particle filtering (PF) is used to estimate the potential loss $L_{\text {tol }}$ in real time using condition monitoring data (Section 3.2). The quantification of tolerable losses $L_{\mathrm{tol}}$ is, then, discussed in Section 3.3.

\subsection{The integrated modeling framework}

To model the dynamic business continuity, we make the following assumptions:

1) The evolution of the disruptive event is modeled by an event tree (ET). Depending on the states of safety barriers, different consequences can be generated from an initialing event. These consequences can be 
grouped into different categories based on their severities. Each consequence generates a certain amount of loss. However, it should be noted that different consequences might have the same degree of losses. According to their severities, possible consequences of a disruptive event are classified as $C_{i}, i=1,2 \cdots, n$, where $n$ is the number of severity level. The severity and duration of the business interruption corresponds to different losses.

2) Some safety barriers in the ET are subject to degradation failure processes. Condition monitoring data are available for these safety barriers at predefined time instants $t_{k}, k=1,2, \cdots, q$.

3) The other safety barriers have constant failure probabilities.

4) Recovery means repairing the failed component and restarting the business. The time for the recovery from consequence $C_{i}$ is a random variable $t_{\text {recv }, i}$, with a probability density function (PDF) $f_{\text {recv }, i}$.

An integrated framework for DBCA is presented in Figure 1. The DBCA starts from collecting condition monitoring data, denoted as $c_{k}$, which is collected from sensors and can be used to characterize the degradation states of the component. The degradation of the safety barriers is estimated based on the condition monitoring data and used to update the estimated losses. Then, the potential profits are predicted and used to calculate the tolerable losses. Finally, the dynamic business continuity metrics can be calculated.

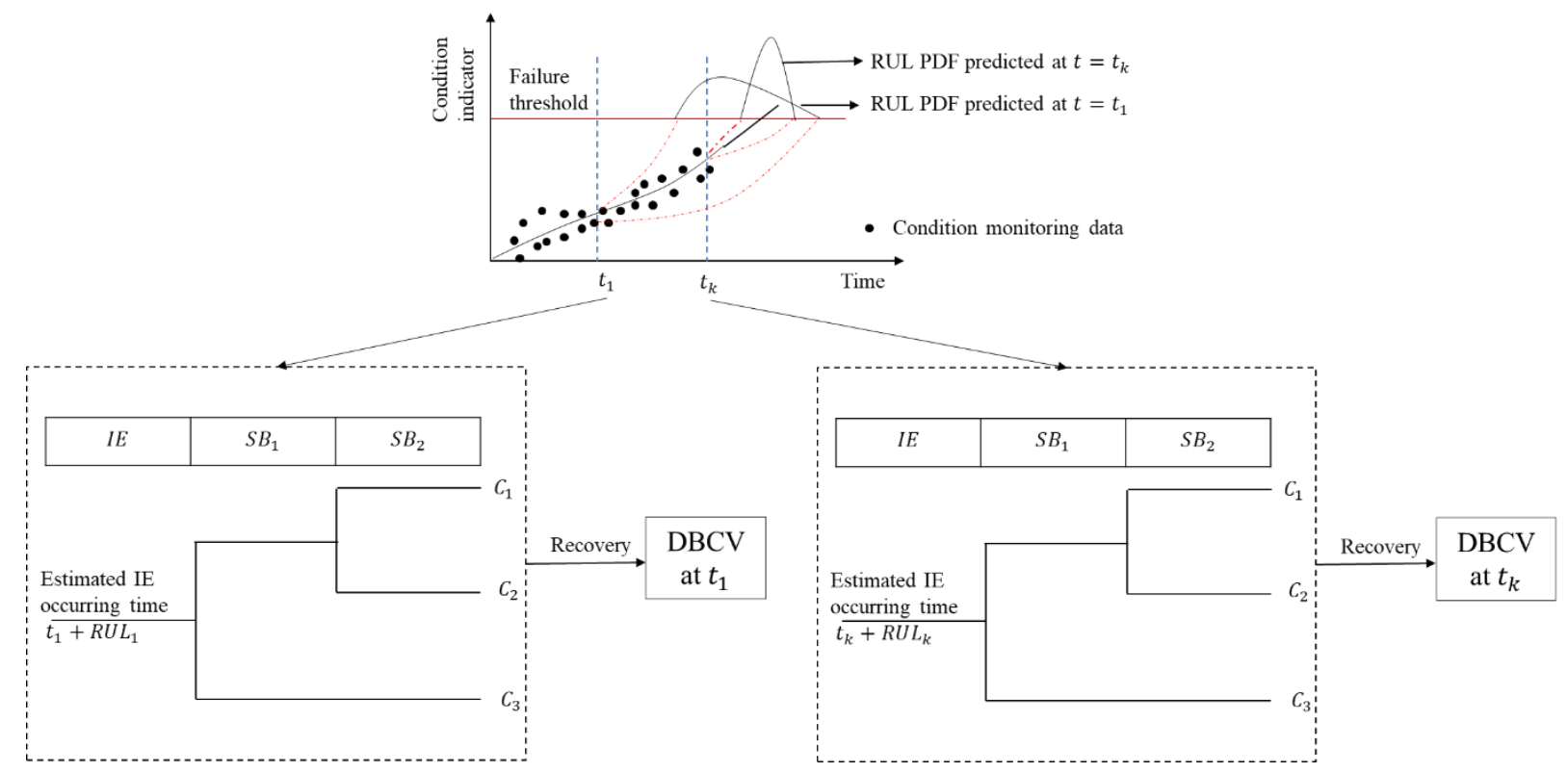

Figure 1. Integrated modeling framework for DBCA.

\section{$235 \quad 3.2$ Loss modeling}

To capture the dynamic failure behavior of a safety barrier as it ages in time, PF is employed in this work to 
238 is applied because of its capability of dealing with the complex non-linear dynamics and non-Gaussian noises that 239 are often encountered in practice $[42,43]$.

240 Suppose the degradation process of a safety barrier can be described by Equation (7), in which the current state $241 x_{k}$ at the $k$-th discrete time step depends on the previous state $x_{k-1}$. Here, $f$ is a non-linear function and $v_{k}$ represents process noise that follows a known distribution. In practice, Equation (7) is often determined based on 243 physics-of-failure models [39]:

$$
\mathbf{x}_{k}=f\left(\mathbf{x}_{k-1}, v_{k}\right)
$$

where $h$ is the observation function (possibly nonlinear), $\boldsymbol{\sigma}_{k}$ is the observation noise vector sequence of known distribution. The measurement data $\mathbf{z}_{k}$ are assumed to be conditionally independent given the state process $\mathbf{x}_{k}$. Equation (8) quantifies the observation noise from the sensors.

The PF follows two steps [44]:

1) Filtering step, where the available condition monitoring data $z_{k}$ are used to estimate the current degradation state of the system.

2) Prediction step, in which the RUL is predicted based on the estimated degradation state and the condition monitoring data.

In the filtering step, the posterior PDF of variable $\mathbf{x}_{k}$ is approximated by the sum of weighted particles $\left\{\mathbf{x}_{k}^{(i)}, \omega_{k}^{(i)}\right\}:$

8

$$
p\left(\mathbf{x}_{k} \mid z_{1}, z_{2}, \cdots, z_{k}\right) \approx \sum_{i=1}^{N_{s}} \omega_{k}^{(i)} \delta\left(\mathbf{x}_{k}-\mathbf{x}_{k}^{(i)}\right)
$$

where $p\left(\mathbf{x}_{k} \mid z_{1}, z_{2}, \cdots, z_{k}\right)$ is the estimated posterior PDF of $\mathbf{x}_{k}, \delta$ is the Dirac Delta function, $\omega_{k}^{(i)}$ is the weight assigned to particle $\mathbf{x}_{k}^{(i)}$ and is generated by sequential importance sampling [32]. When the new measurement $z_{k}$ is available, the required posterior distribution of the current state $x_{k}$ can be obtained by updating the prior distribution: 


$$
p\left(\mathbf{x}_{k} \mid \mathbf{z}_{k}\right)=\frac{p\left(z_{k} \mid \mathbf{x}_{k}\right) p\left(\mathbf{x}_{k} \mid \mathbf{z}_{k-1}\right)}{\int p\left(z_{k} \mid \mathbf{x}_{k}\right) p\left(\mathbf{x}_{k} \mid \mathbf{z}_{k-1}\right) d \mathbf{x}_{k}}
$$

264 where $p\left(z_{k} \mid \mathbf{x}_{k}\right)$ is the likelihood function that can be derived from the observation function (8). Generally, if the 265 samples $\mathbf{x}_{k}^{(i)}$ are drawn from the sampling distribution $p\left(\mathbf{x}_{k} \mid \mathbf{z}_{k}\right)$, then, the particle weight can be updated with 266 a new observation $z_{k}$, as follows [32]:

$$
\omega_{k}^{(i)}=\omega_{k-1}^{(i)} \frac{p\left(\mathrm{z}_{k} \mid \mathbf{x}_{k}^{(i)}\right) p\left(\mathbf{x}_{k}^{(i)} \mid \mathbf{x}_{k-1}^{(i)}\right)}{p\left(\mathbf{x}_{k}^{i} \mid \mathbf{x}_{0: k-1}^{i}, \mathbf{z}_{k}\right)} .
$$

Note that the weights are normalized as $\sum_{i=1}^{N_{s}} \omega_{k}^{(i)}=1$.

Algorithm 1 summarizes the major steps of PF [45].

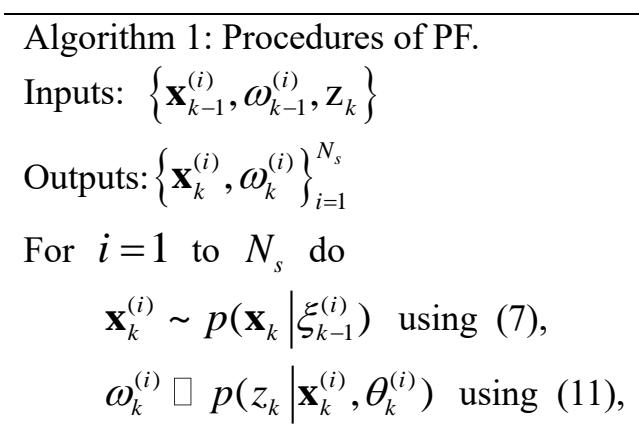

End for

For $i=1$ to $N_{s}$ do

$$
\omega_{k}^{(i)} \leftarrow \omega_{k}^{(i)} / \sum_{i=1}^{N_{s}} \omega_{k}^{(i)}
$$

End for

$$
\begin{aligned}
& N_{\text {eff }} \leftarrow\left(\sum_{i=1}^{N_{s}}\left(\omega_{k}^{(i)}\right)^{2}\right)^{-1} \\
& \text { If } N_{\text {eff }}<N_{s} \text { then } \\
& \qquad\left\{\mathbf{x}_{k}^{(i)}, \omega_{k}^{(i)}\right\}_{i=1}^{N_{s}} \leftarrow \text { resample }\left(\left\{\mathbf{x}_{k}^{(i)}, \omega_{k}^{(i)}\right\}_{i=1}^{N_{s}}\right)
\end{aligned}
$$

End if

$$
\text { Return }\left\{\mathbf{x}_{k}^{(i)}, \omega_{k}^{(i)}\right\}_{i=1}^{N_{s}}
$$

Then, in the prediction step, the RUL associated to the $i$-th particle at $t=t_{k}$ can be estimated through state

271 function (7) by simulating the evolution trajectory of the particles until they reach the failure threshold $z_{t h}$ :

$$
R U L_{k}^{(i)}=\left\{\left(T_{t h}^{(i)}-1-k\right) \mid x_{T_{t h}^{(i)}-1}<z_{t h}, x_{T_{t h}^{(i)}} \geq z_{t h}\right\},
$$


where $T_{t h}^{(i)}$ is the first time the particle reaches the threshold $z_{t h}$. Thus, the PDF of the RUL can be generated by:

$$
p\left(R U L \mid \mathbf{z}_{k}, z_{t h}\right) \approx \sum_{i=1}^{N_{s}} \omega_{k}^{(i)} \delta\left(R U L-R U L_{k}^{(i)}\right)
$$

The predicted $R U L_{k}^{(i)}, i=1,2, \cdots, N_{s}$ can, then, be used in a simulation process to generate samples of the total per unit of time.

Algorithm 2: Generating samples for the losses

Input: $\left\{R U L_{k}^{(i)}, \omega_{k}^{(i)}\right\}_{i=1}^{N_{s}}, T$

Output: $L_{k}^{(i)}$

Initial value $L_{k}^{(i)}=0, t=0, t_{1}=0, T=t_{k}+T, t_{2}=0$;

$R U L_{p s e u d o, k} \leftarrow$ randomly select one element from $\left\{R U L_{k}^{(i)}\right\}_{k=1}^{N_{p}}$, where $R U L_{k}^{(i)}$ is selected with probability $\omega_{k}^{(i)}$

Calculate $T_{k}^{(i)}=t_{k}+R U L_{p s e u d o, k}$

$\rightarrow$ While $t<T$

$t_{1}=t ; t_{1}=t_{1}+T T F_{k}^{(i)}$

$\rightarrow$ if $t_{1}>T$

$L_{k}^{(i)}=L_{k}^{(i)}$

else

Using the event tree determine the consequence;

Using the $f_{\text {recv }, i}$ generate the $t_{\text {rec }}$;

$t_{2}=t_{1}+t_{\text {recv }}$;

$\rightarrow$ If $t_{2}>T$

$$
L_{k}^{(i)}=L_{k}^{(i)}+L_{d}+\left(T-t_{2}\right) \cdot P_{I D}
$$

else $t=t_{2}$

$$
L_{k}^{(i)}=L_{k}^{(i)}+L_{d}+t_{\text {recv }} \cdot P_{I D}
$$

$\rightarrow$ end if

end if

$\rightarrow$ end while

\subsection{Tolerable losses modeling}

Budget limitations are the primary driver of resilience-enhancing investments [46], which influence protection,

prevention, and recovery capabilities of system. Tolerable losses $L_{t o l}$ depend on the cash flow of the company and also the risk appetite of the decision maker [13]. In this paper, we assume that at $t_{k}$, the organization can tolerate up to $\alpha$ (in percentage) of its cash flow $Q\left(t_{k}\right)$ at $t_{k}$ :

$$
L_{t o l}\left(t_{k}\right)=Q\left(t_{k}\right) \cdot \alpha
$$


285 For example, $\alpha=0.1$ means $10 \%$ of the current cash flow can be used to withstand potential losses caused by a 286 disruptive event. In practice, the value of $\alpha$ should be determined by the decision maker and reflects his/her risk 287 appetite.

288 We make the following assumptions to model the dynamic behavior of cash flows:

(1) At $t=0$, there is an initial capital of $Q_{0}$.

(2) Installment is used for the company to purchase the asset, where an equal repayment of $C_{p}$ is payed each month for $N_{P}$ months.

It is noteworthy that the cash flow $Q(t)$ depends on the profit earned by the normal operation of the asset: details):

where $I N_{\text {tol }}$ denotes the total investment and equals the whole value of the system, $D_{p}$ represents the down payment, $\rho$ is the interest rate, $\Psi$ is an indicator function:

where $N_{P}$ is the repayment period.

\section{Application}

In this section, we consider the development of DBCA in a case study regarding a disruptive initialing event for

$$
\psi=\left\{\begin{array}{l}
1, \text { if } t \leq N_{P} \\
0, \text { otherwise }
\end{array}\right.
$$

308 the initialing event being the steam generator tube rupture (SGTR). 
The targeted system is briefly introduced in Section 4.1. Subsequently, in Section 4.2, the RUL prediction for a

310 SGTR and the modeling of the potential losses are conducted. The time-dependent $L_{\text {tol }}$ is calculated in Section 4.3.

311 The results of the DBCA are presented and discussed in Section 4.4.

\section{4.1 System description}

313 For illustrative purposes, it is assumed that the NPP has one reactor with a capacity of 550 MW. It is also 314 assumed that the NPP is subject to the threat of only one disruptive event, the SGTR. The whole value of the NPP is $31510^{9} €$ and the operator purchases the NPP using an installment, where the down payment is $5 \cdot 10^{8} €$ and the repayment period is 10 years with an interest rate of $2 \%$.

SGTR is a potential accident that is induced by the degradation of the tubes in the steam generator, which can lead to tube cracking and rupture [50]. Steam generator tubes transfer the heat from the reactor core to the cooling water that is transformed into steam to drive turbines and produce electricity [49]. The steam generator tube is often manufactured with alloy material to attain high structural integrity and prevent leakage of radioactive materials. An ET has been developed for the probabilistic risk assessment (PRA) of the SGTR for a NPP in South Korea, as shown in Figure 2. In Figure 2, eight safety barriers ( $S B_{1} \square S B_{8}$ ) are designed to control the accident and mitigate its impact (Table 1). Depending on the states of the safety barriers, 28 sequences are generated ( $S_{1} \square S_{28}$ ). Based on the degree of their severities, the consequence of the sequences can be categorized into two groups. The first group,

$$
C_{S 1}=\left\{S E_{1}, S E_{2}, S E_{4}, S E_{6}, S E_{7}, S E_{9}, S E_{11}, S E_{12}, S E_{14}, S E_{16}, S E_{20}, S E_{24}\right\}
$$

represents the event sequences in which a SGTR occurs but the consequence is contained by the safety barriers without causing severe damages. The remaining event sequences form the second group $C_{S 2}$ and represent severe consequences of core damage. Regarding $C_{S 1}$, albeit no severe losses are caused, normal production of the NPP is disturbed because the ruptured tube has to be repaired. For $C_{S 2}$, it is assumed that the NPP has to be shut down permanently and the losses incurred are denoted by $C_{\mathrm{CD}}$. 


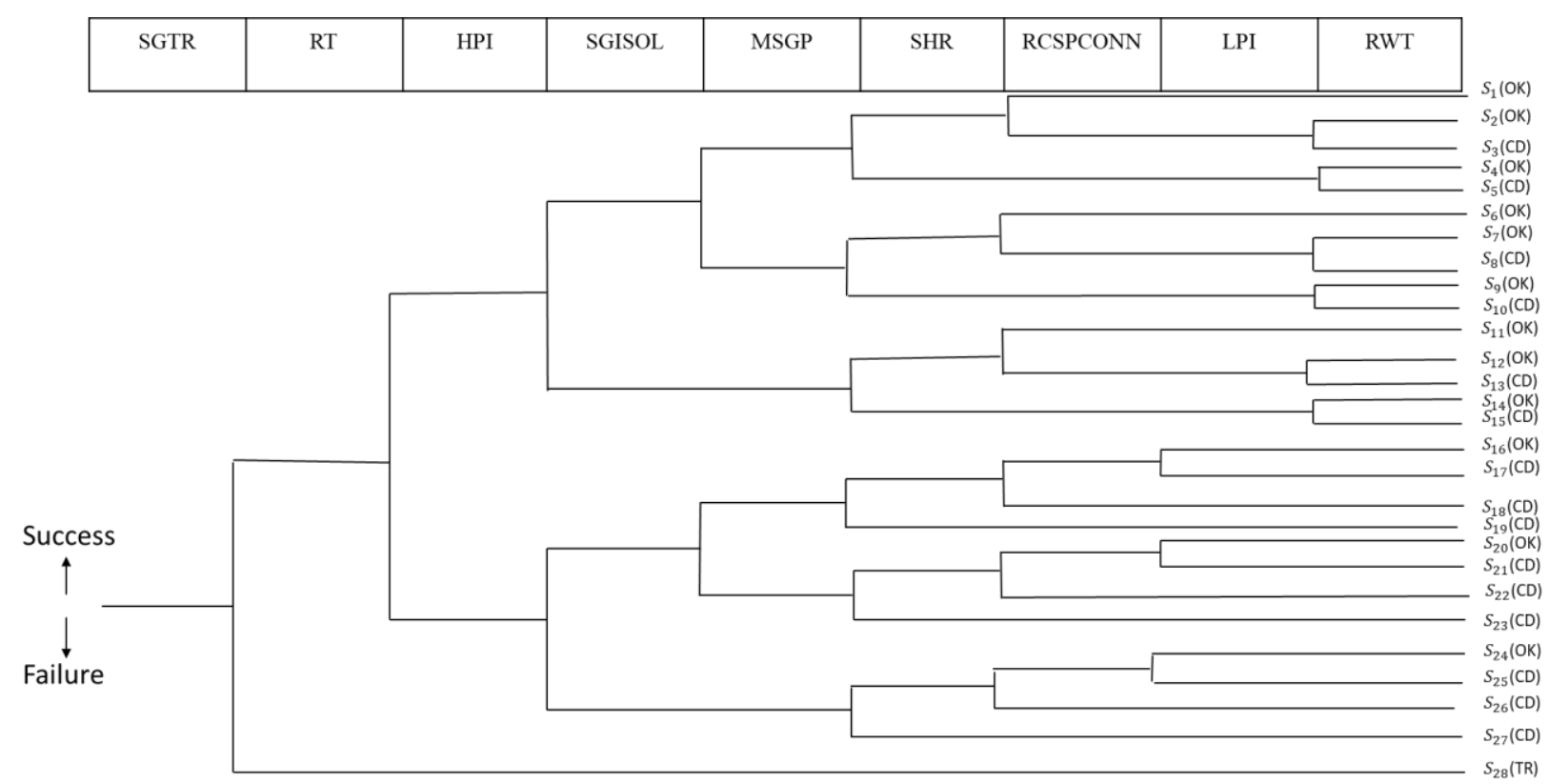

Figure 2. ET for SGTR accident initialing event [49].

Table 1. Safety barriers in the target system [51, 52].

\begin{tabular}{|c|c|c|}
\hline Safety barrier & Failure probability & Description \\
\hline Reactor trip (RT) & $P_{\mathrm{RT}}=1.8 \times 10^{-4}$ & $\begin{array}{l}\text { When there is off-normal condition, the protection system } \\
\text { automatically inserts control rods into the reactor core to } \\
\text { shut down the nuclear reaction. }\end{array}$ \\
\hline High pressure safety injection (HPI) & $P_{\mathrm{HPI}}=4.6 \times 10^{-4}$ & $\begin{array}{l}\text { Inject cool water (at a pressure of about } 13.79 \mathrm{MPa} \text { ) into the } \\
\text { reactor coolant system (RCS) to cool the reactor core and } \\
\text { provide RCS inventory make-up. }\end{array}$ \\
\hline Main steam isolation valve (SGISOL) & $P_{\mathrm{SGI}}=1.0 \times 10^{-4}$ & A valve used to isolate the affected steam generator (SG). \\
\hline $\begin{array}{l}\text { Maintain the affected SG pressure } \\
\text { (MSGP) }\end{array}$ & $P_{\mathrm{M}}=1.5 \times 10^{-4}$ & Maintain the affected SG pressure through the pressurizer. \\
\hline Secondary heat removal (SHR) & $P_{\mathrm{SHR}}=3.4 \times 10^{-5}$ & Heat removal by unaffected SG. \\
\hline $\begin{array}{l}\text { Reactor coolant system pressure control } \\
\text { (RCSPCON) }\end{array}$ & $P_{\mathrm{RCSM}}=1.0 \times 10^{-2}$ & $\begin{array}{l}\text { Open the turbine bypass valve to control the secondary side } \\
\text { pressure. }\end{array}$ \\
\hline Low pressure safety injection (LPI) & $P_{\mathrm{LPI}}=4.6 \times 10^{-4}$ & $\begin{array}{l}\text { Inject cool water (at a pressure of about } 1.03 \mathrm{MPa} \text { ) to cool } \\
\text { down the RCS and provide RCS inventory make-up. }\end{array}$ \\
\hline Refill RWT (RWT) & $P_{\mathrm{RWT}}=2.4 \times 10^{-8}$ & Refill water storage tank. \\
\hline
\end{tabular}

The crack growth process that leads to SGTR can be monitored through non-destructive inspection (e.g., ultrasonic testing [53], eddy current testing [54]). In practice, this is done during planned shutdowns of the NPP, often during the refueling stage. The condition monitoring data collected from these inspections are, then, used for the dynamic business continuity assessment.

\subsection{Particle filtering and loss modeling}

The first step is to update the occurrence probability of the initiating event, based on the condition monitoring data. It is noteworthy that, due to the lack of real data, the condition monitoring data employed in the case study is 
generated from a known physical model. For illustrative purposes, the evolution of the tube crack growth process is assumed to follow the Paris-Erdogan model, which has been applied to model SGTR in [52, 55],

$$
\frac{\mathrm{d} a}{\mathrm{~d} t}=C(\Delta K)^{m}, \Delta K=\Delta \sigma \sqrt{\pi a},
$$

where $a$ is the crack length, $C$ and $m$ are constant parameters related to the component material properties, $\Delta K$ is the stress intensity factor, $\Delta \sigma$ is the stress range. The model can be rewritten in the form of a state transition function [56]:

$$
z_{k}=a_{k}+\delta_{k},
$$

where $\delta_{k}$ is the observation noise with $\delta_{k} \sqcap N\left(0, \delta_{o}^{2}\right)$.

Due to environment and measurement noise, the measured crack lengths are different from the true values. In this paper, we generate the true value of cracks in Figure 3 using a theoretical model with known parameters and generate the observation data by adding a random noise. The purpose of using PF is to estimate the true crack length 354 from the noised observation data and predict the RUL. The number of particles simulated is $N_{s}=5000$. It should 355 be noted that for the tube degradation process, the state vector $\mathbf{x}$ includes the crack size $a$ and the model 356 parameter variables $C, \mathrm{~m}$. The initial values for these variables are drawn uniformly from the intervals of values listed in Table 2:

$$
\left\{\begin{array}{c}
C_{k}=C_{k-1}+N\left(0, \sigma_{c}^{2}\right) \\
m_{k}=m_{k-1}+N\left(0, \sigma_{m}{ }^{2}\right)
\end{array} .\right.
$$

Table 2. Initial intervals for the parameters.

\begin{tabular}{cc}
\hline Parameters & Initial interval \\
\hline$C$ & {$[0.1,0.2]$} \\
$\sigma_{c}$ & {$[1.1,1.3]$} \\
$\sigma_{m}$ & {$\left[0.9 \times 10^{-3}, 0.2 \times 10^{-2}\right]$} \\
$\sigma_{o}$ & {$\left[0.9 \times 10^{-3}, 0.2 \times 10^{-2}\right]$} \\
\end{tabular}



when more condition monitoring data are available.

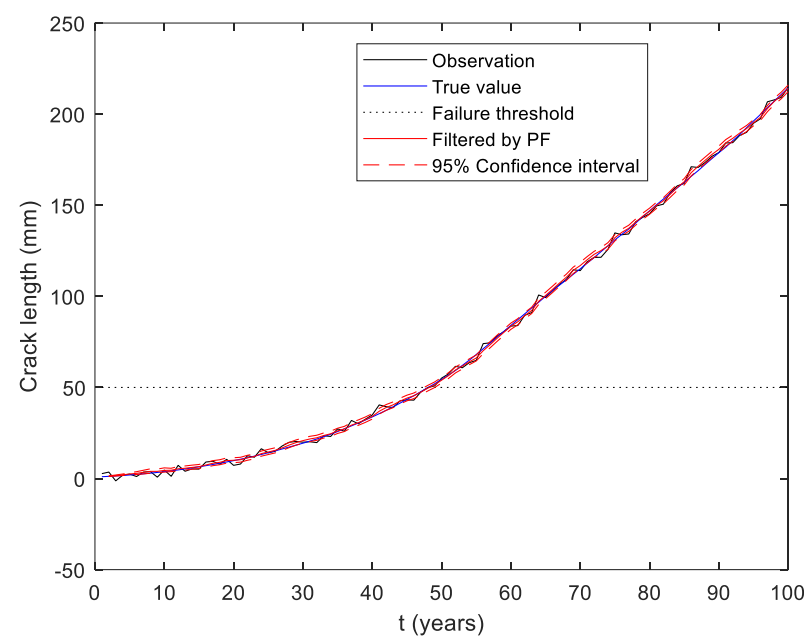

Figure 3. Crack growth process.

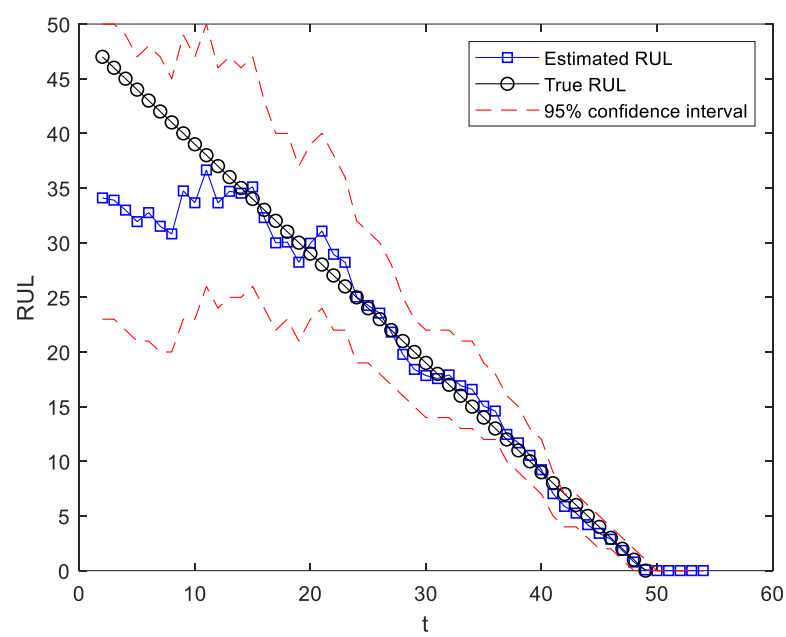

Figure 4. RUL prediction results.

Afterwards, the loss $L([t, t+T])$ in Equation (2) can be calculated. The losses caused by a SGTR event,

include the direct losses and indirect losses. In this case study, the direct losses, denoted by $L_{\mathrm{d}}$, equal to the value

of the damaged equipment. For the consequence $C_{S 1}, L_{\mathrm{d}}$ is identical to the value of the ruptured tube. For the

consequence $C_{S 2}, L$ equals the value of the NPP production since the NPP has to be shutdown. In this paper, we

assume that if $C_{S 2}$ occurs, we have $L=5 \cdot 10^{9} €[57]$

depends on the recovery time and electricity price. Due to the common use of lognormal distribution for modeling the repair process [58-60], we also assume that the recovery time follows a lognormal distribution with the parameters summarized in Table 3, where $\varepsilon$ and $\beta$ are parameters of the lognormal distribution, whose PDF is

$$
f\left(t_{\text {recv }}\right)= \begin{cases}\frac{1}{\sqrt{2 \pi} \beta t_{\text {recv }}} e^{-\frac{\left(\ln \left(t_{\text {rec }}\right)-\varepsilon\right)^{2}}{2 \beta^{2}}}, & t_{\text {recv }}>0 \\ 0, & t_{\text {recv }} \leq 0 .\end{cases}
$$

Then, the value of $L_{\text {in }}$ is calculated by Monte Carlo simulation.

Table 3. Values of the recovery model parameters. 


\begin{tabular}{lll}
\hline$\varepsilon$ & $\begin{array}{l}\text { The mean value of the lognormal } \\
\text { distribution. } \\
\text { The variance value of the lognormal } \\
\text { distribution. }\end{array}$ & 0.1 year $^{2}$ \\
\hline
\end{tabular}

\subsection{Tolerable loss modeling}

We assume that the decision-maker of the NPP determines that the organization can tolerate losses up to $10 \%$ of the cash flow. Therefore, we have $\alpha=0.1$. For the NPP, $I\left(t_{k}\right)$ depends on the electricity price, which often exhibits large variabilities. In this paper, we use the following model, as much as possible incorporating the features of electricity price (such as seasonal volatility, time-varying mean reversion and seasonally occurring price spikes) to simulate the stochastic behavior of the electricity price [61]:

$$
\mathrm{d} x_{t}=\theta \tau(t)\left(\mu_{p}-x_{t}\right) \mathrm{d} t+\sigma \sqrt{\tau(t)} \mathrm{d} W_{t}+\mathrm{d} Z_{t}
$$

where $x_{t}$ is the electricity price at $t, \theta>0$ and $\mu_{p}$ is the mean value of the price, $W_{t}$ is a standard Brownian motion and $Z_{t}$ is a compound Poisson process with levy measure $v(\mathrm{~d} x)=\lambda g(x) \mathrm{d} x, \quad \lambda$ is the jump intensity and $g$ is the density of the jump size distribution, $\tau(t)$ is a positive stochastic process which satisfies:

$$
\tau(t)=s(t)+v(t)
$$

387 where $s(t)$ is a deterministic, time-dependent and positive seasonal component, which is often modeled by a 388 trigonometric function:

$$
S_{1}(t)=a_{1} \sin \left(\frac{a_{2}+2 \pi t}{5}\right)+a_{3}\left(\frac{a_{4}+2 \pi t}{251}\right)+a_{5} .
$$

The value of the seasonal component parameters are shown in Table 4.

Table 4. Values of the seasonal component parameters of the spot prices.

\begin{tabular}{lc}
\hline Parameter & Value \\
\hline$a_{1}$ & 0.41 \\
$a_{2}$ & 1.90 \\
$a_{3}$ & 0.40 \\
$a_{4}$ & 43.11 \\
$a_{5}$ & 0.29 \\
\hline
\end{tabular}


$393 v(t)$ is a stochastic process, representing the stochastic part of the time change. The Cox-Ingersoll-Ross process 394 [62] is used to model $v(t)$,

$$
\mathrm{d} v(t)=\kappa(\eta-v(t)) \mathrm{d} t+\sqrt{v(t) \sigma_{2}} \mathrm{~d} W_{2}(t) .
$$

By using Itô's lemma [61], Equation (24) can be solved and we can derive the following form:

$$
x(t)=x(0)+\int_{0}^{t} \theta(\mu-x(t)) \mathrm{d} t+\int_{0}^{t} \sigma \sqrt{\tau(t)} \mathrm{d} B(t)+\int_{0}^{t} \mathrm{~d} Z(t) .
$$

The parameters of the stochastic electricity model are tabulated in Table 5, which is estimated from the German 399 EEX $^{1}$ (a market platform for energy and commodity products), from 12.03.2009 until 31.12.2013. The interested 400 readers may refer to details and derivations in [61].

Table 5. Parameters in the stochastic electricity model [61].

\begin{tabular}{cc}
\hline Parameter & Value \\
\hline$x_{0}$ & 40 \\
$\Theta$ & 0.22 \\
$\mu$ & 50 \\
$\sigma$ & 5.98 \\
$\mathrm{dt}$ & 1 \\
$\lambda$ & 0.12 \\
$\mu_{1}$ & 1.02 \\
$\sigma_{1}$ & 1.35 \\
\hline
\end{tabular}

403 Eventually, the generated stochastic electricity price trajectory is shown in Figure 5.

\footnotetext{
${ }^{1}$ https://www.eex.com
} 


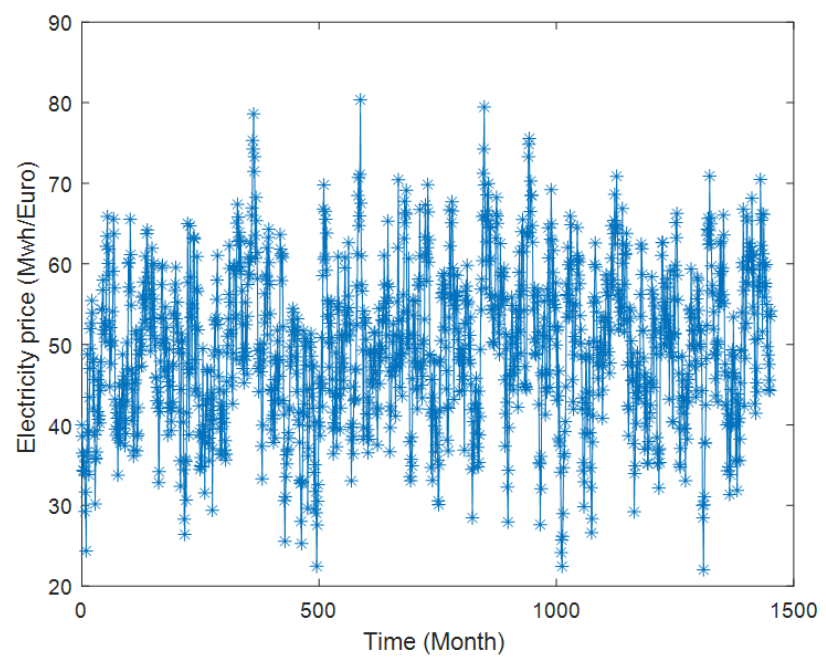

Figure 5. Simulated time-varying electricity price trajectory for 1500 months.

The operation cost $C_{o}\left(t_{k}\right)$ in Equation (15) is set as constant $20 € / \mathrm{MWh}$, which includes the cost of uranium fuel and the cost of disposing used fuel and wastes [63]. Finally, the cash flow at different time points is shown in Figure 6. We can see that the accumulated profit is small at the beginning. This is because this period is still under the repayment period and a large amount of the revenue is used for repaying the installment. After $t=10$ years, the repayment is paid off and, thus, the profit increases significantly.

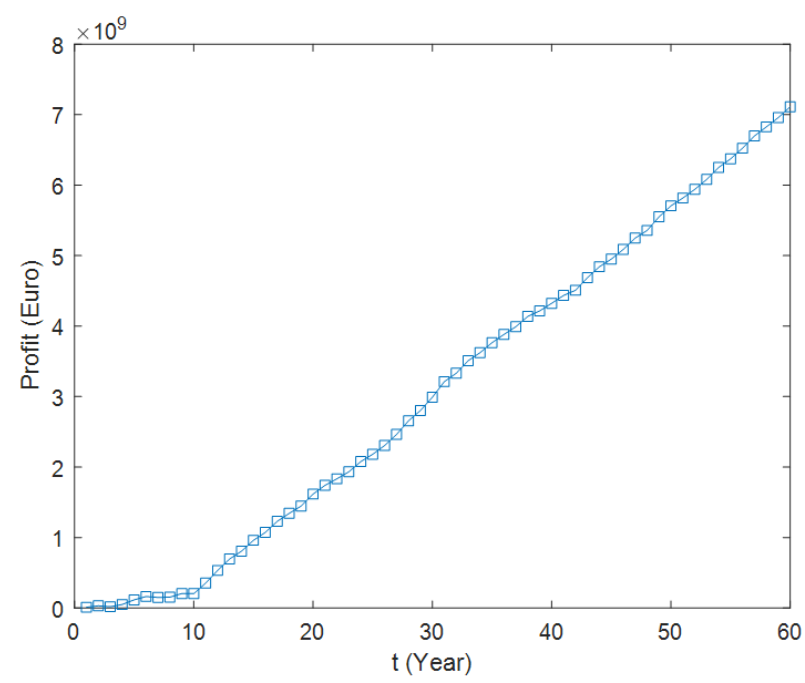

Figure 6. Profit trajectory at different estimation points.

\subsection{Results}

A DBCA is conducted using Algorithm 2. The analyses investigate the dynamic business continuity behavior for the plant at different ages $t=1,2, \cdots, 40$ (years) and under different evaluation horizons $T=1,2, \cdots, 60$ (years), as shown in Figures 7 9. To show the difference between DBCA and (time-static) BCA, a comparison is also carried out. For the BCA, the occurrence of SGTR is assumed to follow a Poisson process, where $\lambda_{s t}=7.0 \times 10^{-3}$ per year 
416 [49]. The estimated time horizon is chosen to be the lifetime of the NPP, $T=60$ years. The time-static business 417 index is defined as:

$$
B C V(0, T)=1-\frac{L(0, T)}{L_{\mathrm{tol}}}
$$

419 where $B C V$ is the business continuity value; $L_{\text {tol }}$ is the tolerable losses and is assumed to be a constant value,

420 which equals $Q_{0}$ (i.e., the initial capital). The recovery time model for the BCA is identical to the one employed in 421 DBCA.

The results from the time-static and time-dependent BCA are compared in Figure 7 9, where the true value is 423 generated based on a theoretical model with known parameters. Abscissa axis shows the estimation horizon $T$, and 424 the vertical axis stands for the different BCV indexes. Therefore, these results show the business continuity of NPPs at different age $(t)$, if it is operated for different lengths of time $(T)$.

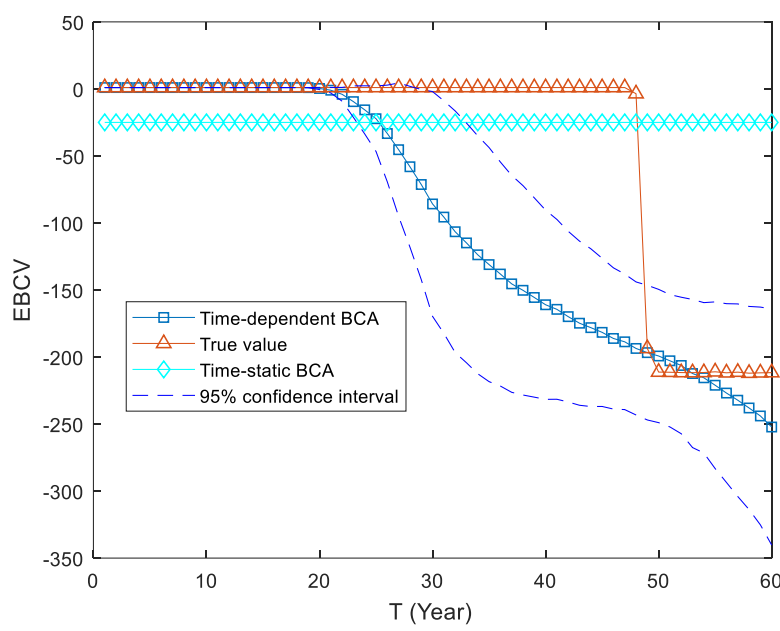

(a) EDBCV

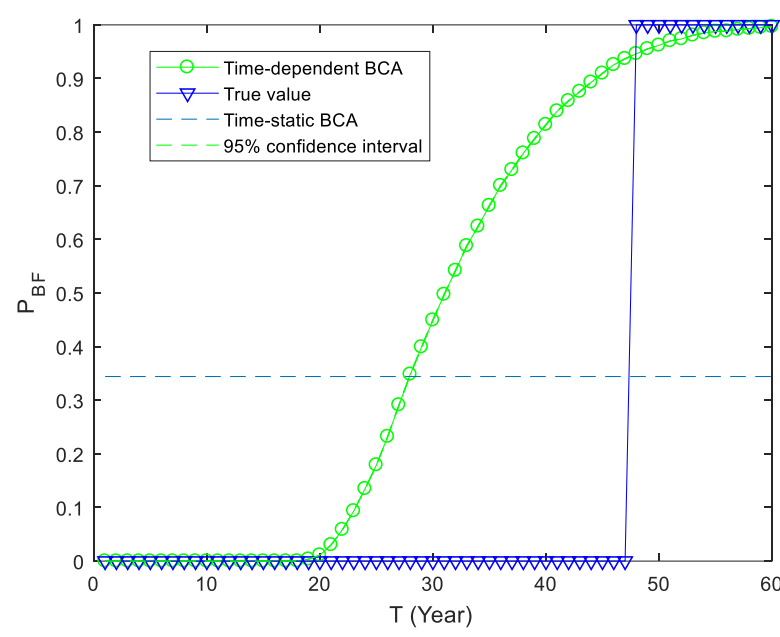

(b) $P_{B F}$

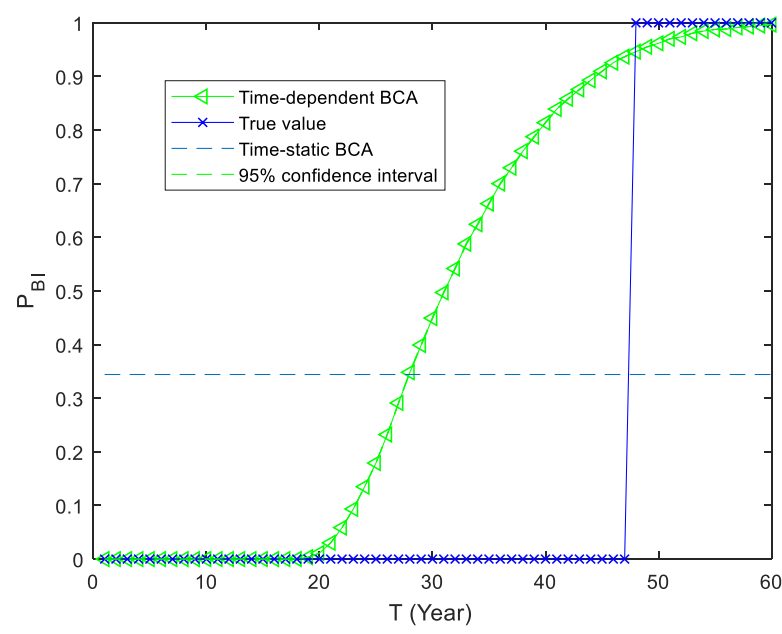

(c) $P_{B I}$ 
Figure 7. Business continuity metrics at $t=1$ year.

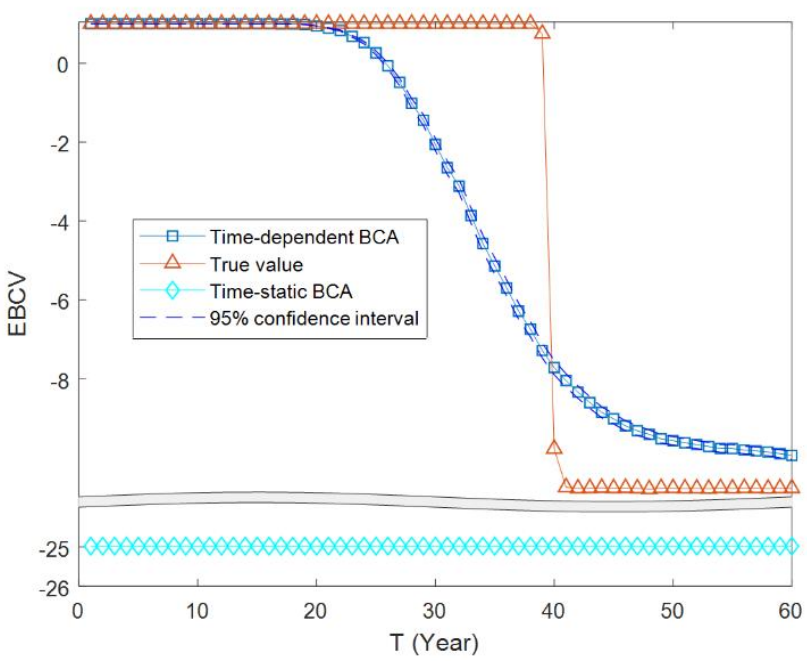

(a) EDBCV

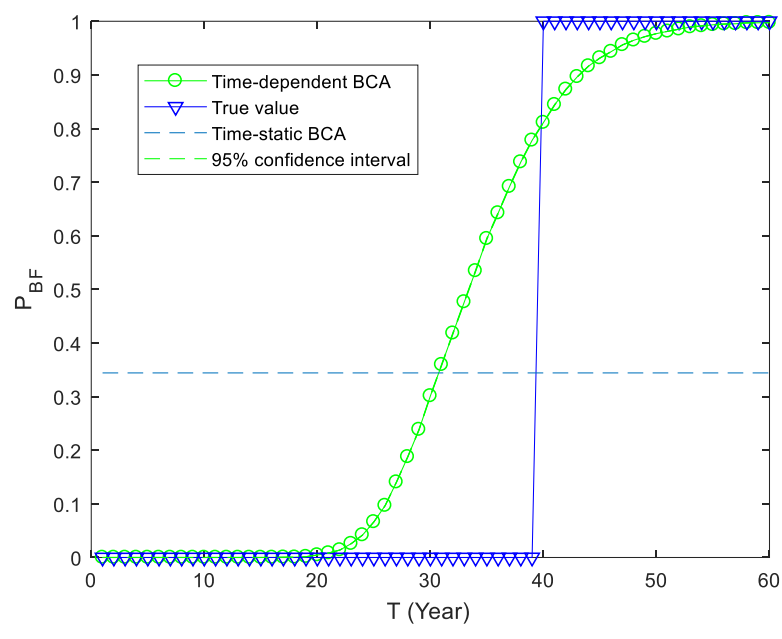

(b) $P_{B F}$

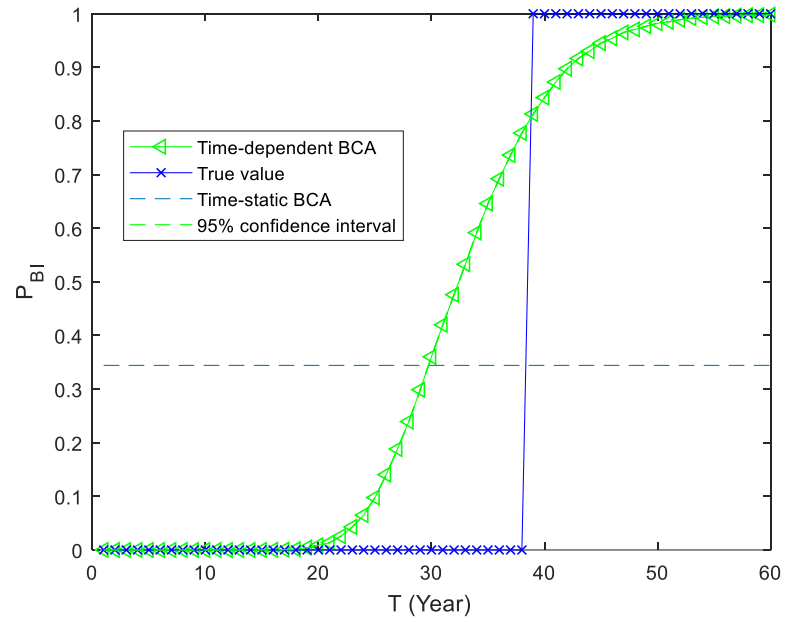

(c) $P_{B I}$

Figure 8 . Business continuity metrics at $t=10$ years.

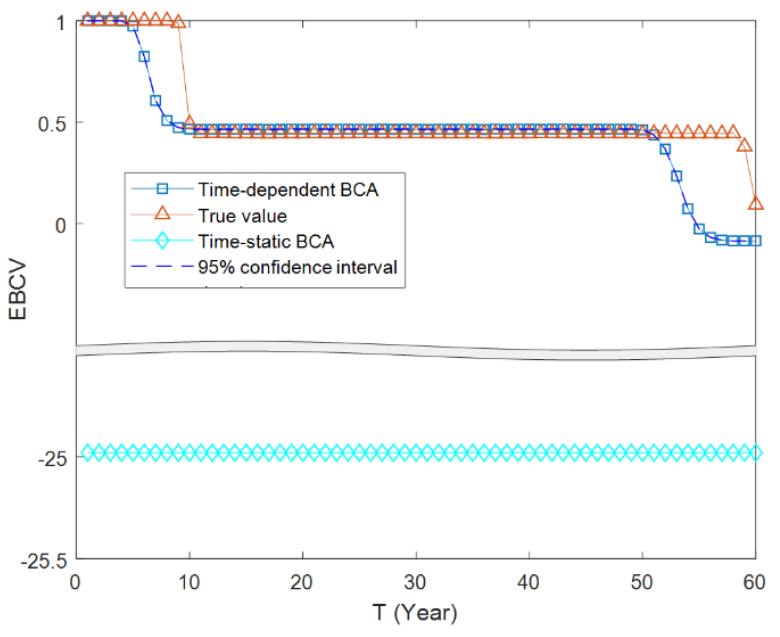

(a) $\mathrm{EDBCV}$

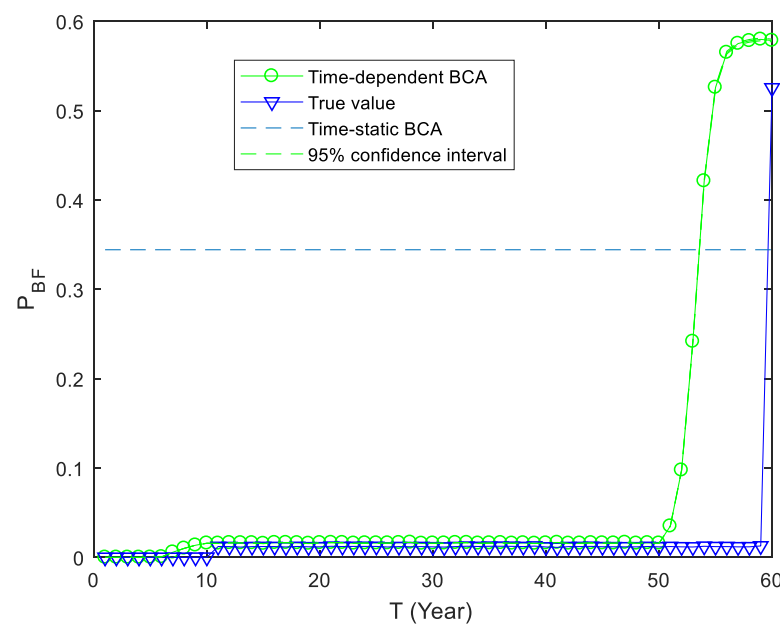

(b) $P_{B F}$ 


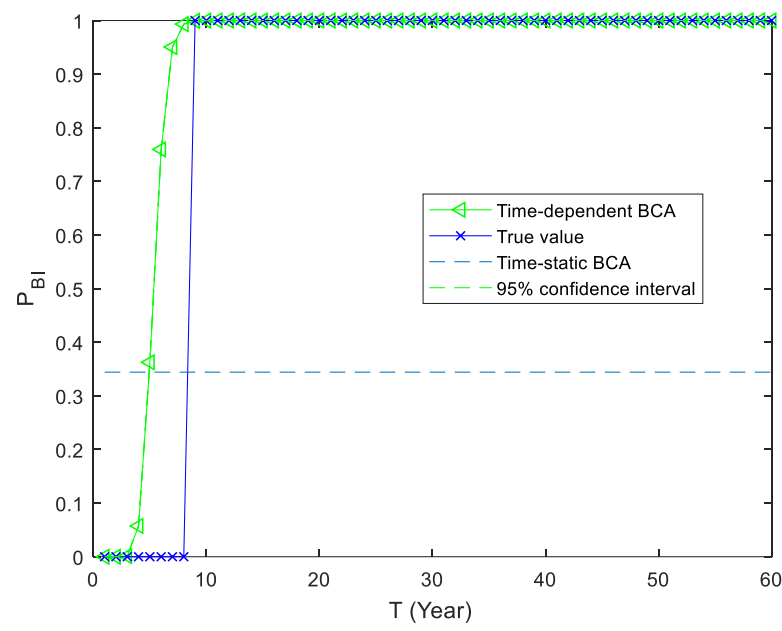

(c) $P_{B I}$

Figure 9 . Business continuity metrics at $t=40$ years.

1) At each $t$, with the increase of the estimation horizon $T$, the DBCV decreases. This means that regardless of the age $t$ of the NPP, the longer the NPP is operated, the worse its business continuity: this is logical, as it is primarily caused by the tube's degradation process. No rupture is supposed to occur at the beginning of system operation. Subsequently, as the crack grows, rupture will occur eventually and lead to system failure. In addition, the dynamic business continuity (DBC) indexes curves drop (Figure 7 (a), Figure 8 (a), Figure 9 (a)) or rise (Figure 7 (b, c), Figure $8(b, c)$, Figure $9(b, c)$ ) significantly after a certain value of $T$. In practice, intervention measures like overhauls need to be taken before this $T$, in order to prevent serious losses from occurring failures and ensure the business continuity.

2) For the same estimation horizon $T$, with the increase of NPP age $t$, the EDBCV moves toward left, which means the financial safety margin is narrowing over time $t$. This is because the steam generator tube is getting closer to a dangerous state as the NPP ages.

3) When $T$ is beyond a certain value, the business continuity metrics becomes invariant. This is mainly because when $T$ is sufficiently long, the rupture event will surely happen and after that no loss occurs any more.

4) There are plateau sections in the curves of EBCV (Figure 7 (a), Figure 8(a), Figure 9 (a)); the height of these plateaus increases with time $t$, which makes sense because the system potential profits increase over time $t$.

5) The comparison between DBCA and time-static BCA shows that the time-static BCA grossly underestimates the damage of SGTR on system business and, thus, underestimates the NPP's business loss. 
Moreover, the results from the DBCA using condition-monitoring data are closer to the true BCV than those of the time-static BCA. This is because the DBCA using condition monitoring data incorporates the time-dependent behavior of SGTR degradation.

\section{Discussion}

In this work, although the developed method is only applied on a case study of NPP, it can also be applied in a wide variety of scenarios. To apply the developed method for DBCA, a system needs to satisfy the following premises: (1) the business continuity is related to financial losses; (2) the system behavior and/or the profit of the system are potentially time-dependent; (3) condition monitoring data are available to describe the time-dependent system behaviors. For instance, in the example of oil storage tanks in [4], the profits of the oil storage tank depend on the price of the oil and are therefore time-dependent. Lithium batteries are used to drive some critical safety barriers. As the Lithium battery is subject to degradation, the performance of the safety barriers is also time-dependent. Besides, condition monitoring data are available from the mounted sensors and can be used for online updating the failure probability of the safety barriers. Therefore, the developed methods can be applied for DBCA of the oil tanks. For IT service, the profits also exhibit time-dependent behaviors. The failure behaviors of the hardware in the IT infrastructure are also time-dependent due to the presence of various degradation failure mechanisms. If condition monitoring data are available to monitor the state of the hardware, the developed model can also be applied for a DBCA.

Compared to the original time-static BCA method, the developed model captures the time-dependent features of both profits and system failure behaviors. Therefore, the proposed method can more precisely quantify the business continuity that exhibits time-dependent behaviors. However, the price we need to pay is that our model is more complex in both model development and analysis. In practice, we often need to choose the most appropriate method based on a tradeoff between the complexity of the modelling and the accuracy of the results. For example, for systems whose failure behavior is not time-dependent or not significant to safety, the traditional time-static BCA method might be sufficient. However, for safety critical systems that have significant time-dependency (e.g., NPP), the developed method is preferred due to its potential to provide a more accurate assessment. 
It should be noted that in this work, we assume that the operation costs (including the inspection and maintenance cost) do not change over time (as seen in Equation (15)). This assumption is reasonable for NPP, because NPPs are usually designed with a large margin so that even though they reach their designed life, their performance does not degrade very severely. However, for other products, these costs might also be time-dependent and increasing with time. This fact should be considered for a more precise modelling.

Moreover, to illustrate the proposed DBCA model, we use a stochastic electricity model to predict the electricity price as it considers a large variety of features contributing to electricity price variations (such as seasonal volatility, time-varying mean reversion and seasonally occurring price spikes). The predicted electricity price is shown in Figure 5. It should be noted that the predicted values here are used to illustrate the developed method only. There are numerous factors that have the potential influence on the electricity price (such as new energy source and new consumption patterns), which make the predicted results inevitably subject to various sources of uncertainty concerning the long-time span for prediction. Therefore, when the developed method is applied in practice, up-todate electricity information should be used, instead of this predicted value, in order to reduce the uncertainty and assessment errors.

It should be noted that in this work, we only look at disruptive events that are caused by safety related hazards. In practice, however, the problem of business continuity might also be caused by disruptive events other than safety related hazards, e.g., strike, natural hazards. The developed models can be extended to capture also these disruptive events.

\section{Conclusions}

In this paper, a DBCA method that integrates condition monitoring data is proposed. Two factors that influence the dynamic behavior of business continuity are considered explicitly. The first one is the dynamics of the degradation-to-failure process affecting the safety barriers. Condition monitoring data are used to update and predict the time-dependent failure behavior by PF. The second factor is the time-dependent profit and tolerable losses. This is quantified by applying a stochastic price model and an installment model. A simulation-based framework is developed to calculate the time-dependent business continuity metrics originally introduced. A case study regarding the analysis of an accident initiated by SGTR in a NPP shows that the proposed framework allows capturing the dynamic character of business continuity.

The outcomes of such dynamic analysis can provide insights to stakeholders and decision-makers, that can help them to identify when best to take actions for preventing serious losses and ensuring business continuity. 


\section{Acknowledgement}

The work of Ms. Jinduo Xing is supported by China Scholarship Council (No. 201506450020). The work by

Professor Enrico Zio has been developed within the research project "SMART MAINTENANCE OF INDUSTRIAL

\section{PLANTS AND CIVIL STRUCTURES BY 4.0 MONITORING TECHNOLOGIES AND PROGNOSTIC}

APPROACHES - MAC4PRO ", sponsored by the call BRIC-2018 of the National Institute for Insurance against

Accidents at Work - INAIL in Italy.

\section{References}

[1] Zio, E., The future of risk assessment. Reliability Engineering \& System Safety, 2018. 177: p. 176-190.

[2] Zhou, L., X. Wu, Z. Xu, and H. Fujita, Emergency decision making for natural disasters: An overview. International Journal of Disaster Risk Reduction, 2018. 27: p. 567-576.

[3] Ouyang, M. and Y. Fang, A mathematical framework to optimize critical infrastructure resilience against intentional attacks. Computer - Aided Civil and Infrastructure Engineering, 2017. 32(11): p. 909-929.

[4] Zeng, Z. and E. Zio, Dynamic Risk Assessment Based on Statistical Failure Data and Condition-Monitoring Degradation Data. IEEE Transactions on Reliability, 2018. 67(2): p. 609-622.

[5] Sahebjamnia, N., S.A. Torabi, and S.A. Mansouri, Integrated business continuity and disaster recovery planning: Towards organizational resilience. European Journal of Operational Research, 2015. 242(1): p. 261-273.

[6] Cerullo, V. and M.J. Cerullo, Business continuity planning: a comprehensive approach. Information Systems Management, 2004. 21(3): p. 70-78.

[7] Baskerville, R., P. Spagnoletti, and J. Kim, Incident-centered information security: Managing a strategic balance between prevention and response. Information \& management, 2014. 51(1): p. 138-151.

[8] Torabi, S.A., H. Rezaei Soufi, and N. Sahebjamnia, A new framework for business impact analysis in business continuity management (with a case study). Safety Science, 2014. 68: p. 309-323.

[9] Rabbani, M., H.R. Soufi, and S.A. Torabi, Developing a two-step fuzzy cost-benefit analysis for strategies to continuity management and disaster recovery. Safety Science, 2016. 85: p. 9-22.

[10] Torabi, S.A., R. Giahi, and N. Sahebjamnia, An enhanced risk assessment framework for business continuity management systems. Safety Science, 2016. 89: p. 201-218.

[11] Zsidisin, G.A., S.A. Melnyk, and G.L. Ragatz, An institutional theory perspective of business continuity planning for purchasing and supply management. International journal of production research, 2005. 43(16): p. 3401-3420.

[12] Zeng, Z. and E. Zio, An integrated modeling framework for quantitative business continuity assessment. Process Safety and Environmental Protection, 2017. 106: p. 76-88.

[13] ISO, ISO 22301, in Societal Security- Business Continuity Management Systems- Requirements2012, International Organization for Standardization: Switzerland.

[14] Tammineedi, R.L., Business continuity management: A standards-based approach. Information Security Journal: A Global Perspective, 2010. 19(1): p. 36-50.

[15] Forbes Gibb, S.B., A framework for business continuity management. International Journal of Information Management, 2006. 26: p. 128-141.

[16] Herbane, B., The evolution of business continuity management: A historical review of practices and drivers. Business history, 2010. 52(6): p. 978-1002.

[17] Snedaker, S., Business continuity and disaster recovery planning for IT professionals. 2013: Newnes.

[18] Miller, H.E. and K.J. Engemann, Using reliability and simulation models in business continuity planning. International Journal of Business Continuity and Risk Management, 2014. 5(1): p. 43-56.

[19] Järveläinen, J., IT incidents and business impacts: Validating a framework for continuity management in information systems. International Journal of Information Management, 2013. 33(3): p. 583-590.

[20] Faertes, D., Reliability of supply chains and business continuity management. Procedia Computer Science, 2015. 55: p. 1400-1409.

[21] Kato, M. and T. Charoenrat, Business continuity management of small and medium sized enterprises: Evidence from Thailand. International journal of disaster risk reduction, 2018. 27: p. 577-587.

[22] Hassel, H. and A. Cedergren, Exploring the Conceptual Foundation of Continuity Management in the Context of Societal Safety. Risk Analysis, 2019.

[23] Bonafede, E., P. Cerchiello, and P. Giudici, Statistical models for business continuity management. Journal of Operational Risk, 2007. 2(4): p. 79-96.

[24] Tan, Y. and S. Takakuwa, Use of simulation in a factory for business continuity planning. International Journal of 
Simulation Modelling, 2011. 10(1): p. 17-26.

[25] Rezaei Soufi, H., S.A. Torabi, and N. Sahebjamnia, Developing a novel quantitative framework for business continuity planning. International Journal of Production Research, 2018: p. 1-22.

[26] Sahebjamnia, N., S.A. Torabi, and S.A. Mansouri, Building organizational resilience in the face of multiple disruptions. International Journal of Production Economics, 2018. 197: p. 63-83.

[27] Zubair, M. and Z. Zhijian, Reliability Data Update Method (RDUM) based on living PSA for emergency diesel generator of Daya Bay nuclear power plant. Safety Science, 2013. 59: p. 72-77.

[28] Nazempour, R., M.A.S. Monfared, and E. Zio, A complex network theory approach for optimizing contamination warning sensor location in water distribution networks. International Journal of Disaster Risk Reduction, 2018. 30: p. 225234.

[29] Aizpurua, J.I., V.M. Catterson, Y. Papadopoulos, F. Chiacchio, and G. Manno, Improved dynamic dependability assessment through integration with prognostics. IEEE Transactions on Reliability, 2017. 66(3): p. 893-913.

[30] Liu, J. and E. Zio, System dynamic reliability assessment and failure prognostics. Reliability Engineering \& System Safety, 2017. 160: p. 21-36.

[31] Fan, M., Z. Zeng, E. Zio, R. Kang, and Y. Chen, A Sequential Bayesian Approach for Remaining Useful Life Prediction of Dependent Competing Failure Processes. IEEE Transactions on Reliability, 2018. 68(1): p. 317-329.

[32] Coussement, K., D.F. Benoit, and M. Antioco, A Bayesian approach for incorporating expert opinions into decision support systems: A case study of online consumer-satisfaction detection. Decision Support Systems, 2015. 79: p. $24-32$.

[33] Sharma, S. and S. Routroy, Modeling information risk in supply chain using Bayesian networks. Journal of Enterprise Information Management, 2016. 29(2): p. 238-254.

[34] Lawler, C.M., M.A. Harper, S.A. Szygenda, and M.A. Thornton, Components of disaster-tolerant computing: analysis of disaster recovery, IT application downtime and executive visibility. International Journal of Business Information Systems, 2008. 3(3): p. 317-331.

[35] Xie, Y., J. Zhang, T. Aldemir, and R. Denning, Multi-state Markov modeling of pitting corrosion in stainless steel exposed to chloride-containing environment. Reliability Engineering \& System Safety, 2018. 172: p. 239-248.

[36] Mayén, J., A. Abúndez, I. Pereyra, J. Colín, A. Blanco, and S. Serna, Comparative analysis of the fatigue short crack growth on Al 6061-T6 alloy by the exponential crack growth equation and a proposed empirical model. Engineering Fracture Mechanics, 2017. 177: p. 203-217.

[37] Compare, M., F. Martini, S. Mattafirri, F. Carlevaro, and E. Zio, Semi-Markov model for the oxidation degradation mechanism in gas turbine nozzles. IEEE Transactions on Reliability, 2016. 65(2): p. 574-581.

[38] Franke, U., Optimal IT service availability: Shorter outages, or fewer? IEEE Transactions on Network and Service Management, 2011. 9(1): p. 22-33.

[39] Zio, E. and G. Peloni, Particle filtering prognostic estimation of the remaining useful life of nonlinear components. Reliability Engineering \& System Safety, 2011. 96(3): p. 403-409.

[40] Si, X.-S., C.-H. Hu, Q. Zhang, and T. Li, An integrated reliability estimation approach with stochastic filtering and degradation modeling for phased-mission systems. IEEE transactions on cybernetics, 2017. 47(1): p. 67-80.

[41] Corbetta, M., C. Sbarufatti, M. Giglio, and M.D. Todd, Optimization of nonlinear, non-Gaussian Bayesian filtering for diagnosis and prognosis of monotonic degradation processes. Mechanical Systems and Signal Processing, 2018. 104: p. 305-322.

[42] Yu, P., J. Cao, V. Jegatheesan, and L. Shu, Activated sludge process faults diagnosis based on an improved particle filter algorithm. Process Safety and Environmental Protection, 2019. 127: p. 66-72.

[43] Arulampalam, M.S., S. Maskell, N. Gordon, and T. Clapp, A tutorial on particle filters for online nonlinear nongaussian Bayesian tracking. IEEE Transactions on Signal Processing, 2002. 50(2): p. 174-188.

[44] Hu, Y., P. Baraldi, F.D. Maio, and E. Zio, Online Performance Assessment Method for a Model-Based Prognostic Approach. IEEE Transactions on reliability, 2016. 65(2): p. 718-735.

[45] Tulsyan, A., B. Huang, R.B. Gopaluni, and J.F. Forbes, On simultaneous on-line state and parameter estimation in non-linear state-space models. Journal of Process Control, 2013. 23(4): p. 516-526.

[46] Hosseini, S. and K. Barker, Modeling infrastructure resilience using Bayesian networks: A case study of inland waterway ports. Computers \& Industrial Engineering, 2016. 93: p. 252-266.

[47] Lanza, A., M. Manera, and M. Giovannini, Modeling and forecasting cointegrated relationships among heavy oil and product prices. Energy Economics, 2005. 27(6): p. 831-848.

[48] Sullivan, W.G., E.M. Wicks, and J.T. Luxhoj, Engineering economy. Vol. 12. 2003: Prentice Hall Upper Saddle River, NJ.

[49] Kim, H., J.T. Kim, and G. Heo, Failure rate updates using condition-based prognostics in probabilistic safety assessments. Reliability Engineering \& System Safety, 2018. 175: p. 225-233.

[50] Auvinen, A., J. Jokiniemi, A. Lähde, T. Routamo, P. Lundström, H. Tuomisto, J. Dienstbier, S. Güntay, D. Suckow, and A. Dehbi, Steam generator tube rupture (SGTR) scenarios. Nuclear engineering and design, 2005. 235(2-4): p. 457472 .

[51] Mercurio, D., L. Podofillini, E. Zio, and V.N. Dang, Identification and classification of dynamic event tree scenarios via possibilistic clustering: Application to a steam generator tube rupture event. Accident Analysis \& Prevention, 2009. 
618 41(6): p. 1180-1191.

619 [52] Lewandowski, R., R. Denning, T. Aldemir, and J. Zhang, Implementation of condition-dependent probabilistic risk assessment using surveillance data on passive components. Annals of Nuclear Energy, 2016. 87: p. 696-706. [53] Narayanan, M., A. Kumar, S. Thirunavukkarasu, and C. Mukhopadhyay, Development of ultrasonic guided wave inspection methodology for steam generator tubes of prototype fast breeder reactor. Ultrasonics, 2019. 93: p. $112-121$.

624 current steam generator data using artificial neural networks. IEEE Transactions on Instrumentation and Measurement, 2016. 65(3): p. 672-679.

[55] Di Maio, F., F. Antonello, and E. Zio, Condition-based probabilistic safety assessment of a spontaneous steam generator tube rupture accident scenario. Nuclear Engineering and Design, 2018. 326: p. 41-54.

[56] An, D., J.-H. Choi, and N.H. Kim, Prognostics 101: A tutorial for particle filter-based prognostics algorithm using Matlab. Reliability Engineering \& System Safety, 2013. 115: p. 161-169.

[57] Zhu, L., A simulation based real options approach for the investment evaluation of nuclear power. Computers \& Industrial Engineering, 2012. 63(3): p. 585-593.

[58] Arif, A., S. Ma, Z. Wang, J. Wang, S.M. Ryan, and C. Chen, Optimizing service restoration in distribution systems with uncertain repair time and demand. IEEE Transactions on Power Systems, 2018. 33(6): p. 6828-6838.

[59] Ananda, M.M., Confidence intervals for steady state availability of a system with exponential operating time and lognormal repair time. Applied Mathematics and Computation, 2003. 137(2-3): p. 499-509.

[60] Ferrario, E. and E. Zio, Assessing nuclear power plant safety and recovery from earthquakes using a system-ofsystems approach. Reliability Engineering \& System Safety, 2014. 125: p. 103-116.

[61] Borovkova, S. and M.D. Schmeck, Electricity price modeling with stochastic time change. Energy Economics, 2017. 63: p. 51-65.

[62] Hefter, M. and A. Herzwurm, Strong convergence rates for Cox-Ingersoll-Ross processes-full parameter range. Journal of Mathematical Analysis and Applications, 2018. 459(2): p. 1079-1101.

642 [63] Zhu, L. and Y. Fan, Optimization of China's generating portfolio and policy implications based on portfolio theory.

643

644

Energy, 2010. 35(3): p. 1391-1402. 